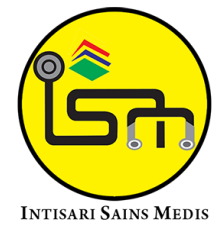

Published by Intisari Sains Medis

\section{Effect of prone positioning for improving oxygenation in awake non-intubated COVID-19 patient: a systematic review}

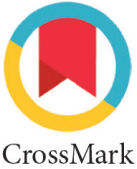

CrossMark

\author{
I Made Yoga Prabawa ${ }^{1 *}$, Dedi Silakarma ${ }^{1}$, Sisca Susantio ${ }^{1}$
}

1Physical and Medical Rehabilitation Department, Faculty of Medicine, Universitas Udayana, Sanglah General Hospital, Bali, Indonesia;

\section{${ }^{*}$ Corresponding author:}

I Made Yoga Prabawa;

Physical and Medical Rehabilitation Department, Faculty of Medicine, Universitas Udayana, Sanglah General Hospital, Bali, Indonesia;

yogaprabawa@unud.ac.id

Received: 2021-10-16

Accepted: 2021-11-30

Published: 2021-12-07

\section{ABSTRACT}

Background: The rapid rise of COVID-19 cases in many regions impacted on increasing needs of intensive care units and oxygen supplementation. The exponential COVID-19 infection with moderate to severe hypoxia that needs oxygen supplementation causes medical oxygen shortage in most hospitals and swamped the health care system. Prone positioning can be an alternate way for non-hospitalized COVID-19 patients, especially in the region facing oxygen and ward shortage in hospitals. This systematic review will describe the impact of the prone positioning method for improving oxygenation in awake non-intubated COVID-19 patients.

Method: A systematic review using PubMed and Google Scholar was conducted based on PRISMA guidelines. We used inclusion criteria such as observational study with cross sectional, cohort, casecontrol or clinical trial study design regarding the effect of prone positioning for improving oxygenation in COVID-19 patients. Exclusion criteria were a letter

to the editor, commentary reports, systematic review or meta-analysis, study involving non-awake and or intubated patients and study not available in full-text. Result: We gathered eleven studies consisting of six retrospective observational studies, three prospective observational studies and two clinical trials comprised of one randomized controlled trial and one interventional study. There are 791 awake nonintubated COVID-19 patients as the study sample. The measured outcomes are changes in $\mathrm{SaO2}, \mathrm{P} / \mathrm{F}$ ratio, $\mathrm{S} / \mathrm{F}$ ratio, ROX index, intubation and mortality rate. The prone positioning duration varies between 29 minutes until 12 hours and helps improve oxygenation, reducing intubation and mortality.

Conclusion: Prone positioning is feasible to apply in awake non-intubated COVID-19 patients. It can improve oxygenation, reduce intubation, mortality rate and be beneficial to overcome oxygen and mechanical intubation shortage during the COVID-19 pandemic.

Keywords: COVID-19 infection, physical therapy, physiotherapy, prone position, SARS-CoV-2.

Cite This Article: Prabawa, I.M.Y., Silakarma, D., Susantio, S. 2021. Effect of prone positioning for improving oxygenation in awake non-intubated COVID-19 patient: a systematic review. Intisari Sains Medis 12(3): 835-841. DOI: 10.15562/ism.v12i3.1191

\section{INTRODUCTION}

Coronavirus disease-19 (COVID-19), since it was first discovered in Wuhan, China, has spread worldwide and was declared a pandemic in March 2020. Until October 2021, the number of COVID-19 cases worldwide reached 244 million cases and 4.95 million cases of death. ${ }^{1}$ The COVID-19 in Indonesia cases went 4.24 million cases with 143.000 cases of death. In July 2021, the COVID-19 case in Indonesia reached the second wave, becoming the worst COVID-19 pandemic situation in Indonesia since the first case on March 2020. ${ }^{2}$ The rapidly daily rise of COVID-19 cases in many regions in Indonesia impacted on increasing needs of intensive care units and oxygen supplementation in many regions in Indonesia. The exponential COVID-19 infection with moderate to severe hypoxia that needs oxygen supplementation causes medical oxygen shortage in most hospitals and swamped the health care system. Many patients died at home or before being taken to the hospital due to shortness of breath and drained medical oxygen supplies. The medical oxygen shortage has turned out to be a significant challenge for the healthcare system in many Indonesian regions. ${ }^{3}$ The major complication contributing to the increased mortality rate in acute respiratory distress syndrome (ARDS) occurs in $20-41 \%$ of patients with severe COVID-19 infection. The ARDS condition often causes patients to fall into a respiratory condition that requires intubation. ${ }^{4}$ Preliminary studies stated that prone positioning helps improve oxygenation marked in increasing oxygen saturation, thus preventing or delaying intubation reducing the mortality rate. Prone positioning can also be an alternate way for non-hospitalized COVID-19 
patients, especially in the region facing oxygen and ward shortage in hospitals..$^{5-10}$

Piehl and Brown firstly stated prone positioning in 1976 that placing the patient with respiratory insufficiency resulted in improved oxygenation. Those findings were in line with a study by Douglas et al. in 1977 that reported a patient with acute lung insufficiency with better oxygenation when she flipped from supine position to prone position. ${ }^{11}$ There is a multifactorial aspect that causes improvement of oxygenation during prone position, but it mainly occurs by minimizing lung compression and maximizing lung perfusion. Alteration in the distribution of extravascular lung fluid and secretions also play a significant role. Prone positioning minimizes the difference between the dorsal and ventral transpulmonary pressure, making ventilation more homogeneous, leading to a decrease in ventral alveolar overinflation and dorsal alveolar collapse. As a result, there is reduced alveolar distension limiting ventilator-associated lung injury and allowing for the opening of alveoli that had collapsed during supine ventilation. ${ }^{11-14}$

Prone positioning could improve oxygenation and decrease respiratory effort; therefore, a prone position might delay or avoid the need for tracheal intubation. The decreasing demand for intubation and intensive care unit admission was beneficial for a condition with a limited resource or in a situation where the COVID-19 cases explode simultaneously. ${ }^{15,16}$ Awake non-intubated prone positioning method has been widely applied by physicians worldwide and proposed in COVID-19 patients by the United Kingdom Intensive Care Society but without solid evidence. ${ }^{13}$ This systematic review will gather evidence regarding the effect of prone positioning in awake and non-intubated COVID-19 patients.

\section{METHODS}

\section{Search strategy}

A comprehensive search for online literature or studies from 2020 until 2021 was conducted. We explored evidence using two databases, including Google Scholar and Pubmed. The keywords used to obtain the relevant study include "prone position" OR "prone positioning" AND "COVID-19" OR "SARS-CoV-2" OR "Coronavirus disease" AND "improving oxygenation" Boolean operator was used to specify the finding result further. We also searched for literature or studies listed in article references and chose a study that fulfilled the eligibility criteria.

\section{Study eligibility}

We included a study with some eligibility criteria using a PRISMA diagram (Figure 1). In the first step, we screened literature from the online database according to the search strategy keywords. We eliminated studies that were irrelevant or duplicated study. Next step, we evaluated the abstract and full text of the study and chose the study that met our inclusion and exclusion criteria. Inclusion criteria that we used were observational study with cross sectional, cohort, case-control or

Potentially relevant studies identified. Titles and abstracts identified and screened $(n=207)$

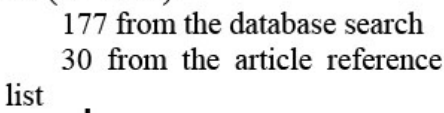

177 from the database search 30 from the article reference list

clinical trial study design regarding the effect of prone positioning for improving oxygenation in COVID-19 patients. Our exclusion criteria were: study such as a letter to the editor, commentary reports, systematic review or meta-analysis, study involving non-awake and or intubated patient and study that not available in fulltext.

\section{Study Selection}

Three reviewers screened all related articles for inclusion based on the topic, study design, and language used in the full text in the study selection process. The abstract was reviewed first, followed by the full version. Last, we assessed the selected literature for their evidence before being included in the final review (Figure 1).

\section{Data Collection}

Identified literature, then merged and managed for further analysis. All of the

Studies meeting inclusion criteria and included in the systematic review $(\mathrm{n}=11)$

Figure 1. The PRISMA diagram of literature selection of this study. 
Table 1. Characteristic of study regarding prone positioning in improving oxygenation in COVID-19 patients.

\begin{tabular}{|c|c|c|c|c|}
\hline Study and study method & $\begin{array}{l}\text { Sample } \\
\text { size (n) }\end{array}$ & $\begin{array}{l}\text { Pruning duration and } \\
\text { method }\end{array}$ & Measured outcome & Result \\
\hline $\begin{array}{l}\text { Burton-Papp et al., 2020, UK } \\
\text { Single-centre retrospective } \\
\text { observational study }\end{array}$ & 20 & $\begin{array}{l}\text { Five cycles, median } \\
\text { duration } 3 \text { hours; prone } \\
\text { position+NIV. }\end{array}$ & $\Delta \mathrm{P} / \mathrm{F}, \Delta \mathrm{RR}, \Delta \mathrm{HR}$ & $\begin{array}{l}\text { Improved oxygenation as measured by a } \\
\text { change in } \mathrm{PaO} 2 / \mathrm{FiO} 2(\mathrm{P} / \mathrm{F}) \text { ratio of } 28.7 \\
\mathrm{mmHg} \text {, but no significant difference in } \\
\text { heart rate or respiratory rate. }^{5}\end{array}$ \\
\hline $\begin{array}{l}\text { Caputo et al., 2020, USA } \\
\text { Observational cohort study }\end{array}$ & 50 & $\begin{array}{l}\text { Median duration } \\
29 \text { minutes; self } \\
\text { proning+supplemental } \\
\text { oxygen via nasal } \\
\text { cannulae or NRM. }\end{array}$ & $\begin{array}{l}\mathrm{SpO}_{2} \text {, rate of } \\
\text { intubation after } 24 \\
\text { hours }\end{array}$ & $\begin{array}{l}\text { Median } \mathrm{SpO} 2 \text { increased to } 94 \% \text { after } 5 \\
\text { minutes prone positioning; } 13 \text { patients } \\
\text { required intubation after } 24 \text { hours } \\
\text { observation in ED. }{ }^{6}\end{array}$ \\
\hline $\begin{array}{l}\text { Coppo et al., 2020, Italy } \\
\text { Prospective cohort study }\end{array}$ & 56 & $\begin{array}{l}\text { Minimum duration } 3 \\
\text { hours a day. }\end{array}$ & $\begin{array}{l}\mathrm{PaO}_{2} / \mathrm{FiO}_{2, \text { the }} \\
\text { feasibility of prone } \\
\text { positioning }\end{array}$ & $\begin{array}{l}\text { Prone positioning is feasible and can } \\
\text { improve oxygenation in awake COVID-19 } \\
\text { patient. }\end{array}$ \\
\hline $\begin{array}{l}\text { Damarla et al., 2020, USA } \\
\text { Retrospective observational } \\
\text { study }\end{array}$ & 10 & $\begin{array}{l}\text { Prone and supine } \\
\text { position alternate every } \\
2 \text { hours during the day } \\
\text { and sleep in } \\
\text { a prone position at night. }\end{array}$ & $\begin{array}{l}\text { Change in oxygen } \\
\text { saturation }\left(\mathrm{SaO}_{2)} \text { and }\right. \\
\text { respiratory rate }(\mathrm{RR})\end{array}$ & $\begin{array}{l}\text { Increase median } \mathrm{SaO}_{2} \text { from } 94 \% \text { to } 98 \% \\
\text { and reduce median } \mathrm{RR} \text { from } 31 \mathrm{x} / \mathrm{min} \text { to } \\
22 \mathrm{x} / \text { min. }^{8}\end{array}$ \\
\hline $\begin{array}{l}\text { Fazzini et al., 2021, UK } \\
\text { Prospective cohort study }\end{array}$ & 48 & $\begin{array}{l}\text { As long as the patient } \\
\text { tolerated; prone position } \\
\text { combined with face } \\
\text { mask oxygen, HFNO or } \\
\text { CPAP. }\end{array}$ & $\begin{array}{l}\mathrm{P} / \mathrm{F} \text { ratio, } \mathrm{S} / \mathrm{F} \text { ratio, } \\
\text { change in } \mathrm{RR}, \mathrm{ICU} \\
\text { admission }\end{array}$ & $\begin{array}{l}\text { Increased in } \mathrm{P} / \mathrm{F} \text { ratio }(115 \pm 43 \mathrm{mmHg} \text { vs. } \\
148 \pm 70 \mathrm{mmHg}) \text { and } \mathrm{S} / \mathrm{F} \text { ratio }(141 \pm 37 \text { vs. } \\
188 \pm 49) \text {. Reduced in RR ( } 45 \text { vs. } 19) \text {. Lower } \\
\text { ICU admission in patients tolerating } \mathrm{PP}>1 \\
\text { hour vs } \leq 1 \text { hour ( } 41 \% \text { vs } 83 \%) .{ }^{9}\end{array}$ \\
\hline $\begin{array}{l}\text { Jagan et al., 2020, USA, } \\
\text { Retrospective observational } \\
\text { study }\end{array}$ & 105 & $\begin{array}{l}\text { Self-prone } \geq 1 \text { hour, five } \\
\text { times during the day and } \\
\geq 1 \text { hour overnight. }\end{array}$ & $\begin{array}{l}\text { S/F ratio, in-hospital } \\
\text { mortality, intubation } \\
\text { rate }\end{array}$ & $\begin{array}{l}\text { Mortality and intubation rate significantly } \\
\text { higher in non-prone patient ( } 24.6 \% \text { vs } 0 \% \\
\text { and } 10 \% \text { vs } 27.2 \%){ }^{10}\end{array}$ \\
\hline $\begin{array}{l}\text { Jouffroy et al., 2021, France } \\
\text { Retrospective observational } \\
\text { study }\end{array}$ & 379 & $\begin{array}{l}\text { Spontaneously breathing } \\
\text { prone position (SBPP) } \\
\text { 3-6 hr twice daily. }\end{array}$ & $\mathrm{PaO} 2 / \mathrm{FiO} 2, \mathrm{PaCO} 2$ & $\begin{array}{l}\text { SBPP was well-tolerated hemodynamically, } \\
\text { increased } \\
\mathrm{PaO} 2 / \mathrm{FiO} 2 \text { ( } 78 \text { vs } 63 \mathrm{mmHg} \text { and } \mathrm{PaCO} 2 \\
\text { ( } 38 \text { vs } 35 \mathrm{mmHg} \text { ) in SBPP patient compare } \\
\text { with non-prone patient. }{ }^{17}\end{array}$ \\
\hline $\begin{array}{l}\text { Kharat et al., 2021, } \\
\text { Switzerland } \\
\text { Randomised controlled trial }\end{array}$ & 27 & $\begin{array}{l}\text { Self-prone positioning } \\
\text { for a maximum of } 12 \\
\text { hours per day. }\end{array}$ & $\begin{array}{l}\text { Oxygen need, S/F } \\
\text { ratio }\end{array}$ & $\begin{array}{l}\text { Lowered oxygen needs and higher median } \\
\text { S/F ratio in the prone patient compared } \\
\text { with the non-prone patient ( } 1.0 \text { vs. } 2.0 \mathrm{~L} / \\
\text { min and } 390 \text { vs. } 336) .{ }^{18}\end{array}$ \\
\hline $\begin{array}{l}\text { Syma et al., } 2020, \text { India } \\
\text { Prospective interventional } \\
\text { study }\end{array}$ & 45 & $\begin{array}{l}\text { PP for a minimum of } \\
2 \text { hours per session and } \\
\text { a target duration of } 8 \\
\text { h/day combined with } \\
\text { conventional oxygen } \\
\text { therapy, NIV, or HFNC. }\end{array}$ & $\begin{array}{l}\text { Rate of intubation } \\
\text { and mortality, ROX } \\
\text { index }\end{array}$ & $\begin{array}{l}\text { The rate of intubation and mortality was } \\
\text { higher in the control group compared with } \\
\text { the PP group ( } 33.3 \% \text { vs. } 6.7 \% ; 26.7 \% \text { vs. } \\
6.7 \%) \text {. But higher ROX index in the PP } \\
\text { group than in the control group ( } 10.7 \text { vs. } \\
6.7) .{ }^{19}\end{array}$ \\
\hline $\begin{array}{l}\text { Winearls et al., 2020, UK } \\
\text { Retrospective observational } \\
\text { study }\end{array}$ & 24 & $\begin{array}{l}\text { Prone position } \\
\text { combined with CPAP }\end{array}$ & $\begin{array}{l}\mathrm{ROX} \text { index, } \mathrm{PaO}_{2} / \\
\mathrm{FiO}_{2}\end{array}$ & $\begin{array}{l}\text { Combination of PP and CPAP } \\
\text { increased ROX index and } \mathrm{PaO}_{2} / \mathrm{FiO}_{2} \\
\text { compared with baseline }(7.0 \pm 2.5 \mathrm{vs} \text {. } \\
11.4 \pm 3.7 \text { and } 143 \pm 73 \text { vs. } 252 \pm 87 \mathrm{~mm} \mathrm{Hg}){ }^{20}\end{array}$ \\
\hline $\begin{array}{l}\text { Wormser et al., 2020, France } \\
\text { Retrospective observational } \\
\text { study }\end{array}$ & 27 & $\begin{array}{l}\text { Prone position without } \\
\text { oxygen supplementation }\end{array}$ & $\begin{array}{l}\mathrm{SpO} 2 / \mathrm{FiO} 2 \text { before, } \\
\text { during, and } \\
\text { after PP, failure rate, } \\
\text { intolerance rate and } \\
\text { adverse events. }\end{array}$ & $\begin{array}{l}\mathrm{SpO} 2 / \mathrm{FiO} 2 \text { ratio was higher during PP } \\
\text { than before ( } 342.5 \text { vs. } 188.5) \text {. The failure } \\
\text { rate was } 5 \% \text {, poor tolerance was } 8 \% \text {, and } \\
\text { adverse events rates were } 7 \% .{ }^{21}\end{array}$ \\
\hline
\end{tabular}

Abbreviation: $\mathrm{CPAP}=$ continuous positive airway pressure, $\mathrm{ED}=$ emergency department, $\mathrm{HFNO}=$ high flow nasal oxygen, $\mathrm{ICU}=$ intensive care unit, $\mathrm{NIV}=$ non-invasive ventilation, $\mathrm{NRM}=$ non-rebreathing mask, $\mathrm{PaO} 2 / \mathrm{FiO} 2=$ ratio of arterial oxygen partial pressure to fractional inspired oxygen, $\mathrm{PP}=$ prone positioning, $\mathrm{SpO} 2=$ oxygen saturation, $\mathrm{P} / \mathrm{F}$ ratio $=\mathrm{PaO} 2 / \mathrm{FiO} 2, \mathrm{~S} / \mathrm{F}$ ratio= $\mathrm{SaO} 2 / \mathrm{FiO} 2, \mathrm{SBPP}=\mathrm{Spontaneously}$ breathing prone position, $\Delta \mathrm{HR}=$ change in heart rate, $\Delta \mathrm{P} / \mathrm{F}=$ change in $\mathrm{PaO} 2$ and $\mathrm{FiO} 2$ ratio, $\Delta \mathrm{RR}=$ change in respiratory rate. 
selected literature was thoroughly read by the reviewers and apprehended to extract the principle of the literature.

\section{Data synthesis}

All relevant studies regarding the effect of prone positioning for improving oxygenation in COVID-19 patients were included in a narrative synthesis. As a qualitative report, this systematic review tried to determine the technique, duration and results of prone positioning for improving oxygenation in COVID-19 patients. The narrative synthesis was conducted systematically to conclude the feasibility, effect, and adverse event of prone positioning in COVID-19 patients.

\section{RESULTS}

Initially, 34 works of literature regarding prone positioning for improving oxygenation in COVID-19 patients were identified. But 23 of them did not meet our inclusion criteria for the study design; they consisted of review, case series, systematic review, and meta-analysis. The other five studies involve non-awake and or intubated patients, and the other two are not available in full text. Finally, only 11 pieces of literature were retrieved to know about the effect of prone positioning for improving oxygenation in COVID-19 patients.

\section{Study Characteristics}

The included studies are six retrospective observational studies, three prospective observational studies, and two clinical trials consisting of one randomized controlled trial and one interventional study. Studies come from several countries such as France, India, Italy, Switzerland, UK and USA. The total sample of all studies is 791 COVID-19 patients. There were $526(66.5 \%)$ male patients and 265 (33.5\%) female patients involved in the studies - the detailed characteristic of the study is described in Table 1.

\section{Quality assessment of the study}

Quality assessment of the study using Joanna Briggs Institute checklist according to each study design. ${ }^{22}$ From eleven studies, nine were cohort studies, one randomized clinical trial and one interventional study. Each item from the checklist contributed to one point. A study is considered good quality if it got half or more maximum total points and regarded as low quality if it got less than the half-maximal total point. The range point varied from 0-11 for the cohort study, $0-13$ for RCT and 0-9 for an interventional study. The two reviewers evaluated the quality of the study to avoid bias. From eleven studies involved, all considered have good quality with total point range from 6-8.

\section{Prone positioning method and duration}

Several prone positioning methods were applied in eleven studies in our systematic review. Seven studies use prone positioning combined with oxygen supplementation via nasal cannula, NRM, NIV and CPAP. And four studies using self-proning without oxygen supplementation, such as a study by Damarla et al., Jagan et al., Jouffroy et al., and Wormser et al., 10,17,21 The proning duration were varied between 29 minutes until a maximum of 12 hours. A study by Caputo et al. asked the patient to do a self-proning position while using supplemental oxygen such as NRM and nasal cannula for about 30-120 minutes, followed by 10-20 minutes in left lateral decubitus, right lateral decubitus, and upright sitting position. ${ }^{6}$ Study by Coppo et al. asked the patient to maintain prone positioning at least 3 hours before going back into a supine position. ${ }^{7}$ Study by Damarla et al. asked the patients to do a prone and supine position alternate every 2 hours during the day and sleep during the night in a prone position supervised by a physician provider. ${ }^{8}$ While study by Fazzini et al. instructed the patients to do pone-positioning as long as the patient tolerated it. ${ }^{9}$ Study by Jagan et al. educated the COVID-19 patients to do self-proning at least one hour for at least five occasions per day and at least one hour during the night. ${ }^{10}$ RCT Study by Kharat et al. asked the prone position group to do the prone position for 12 hours a day and compared it with the control group. ${ }^{18}$ Study by Sryma et al. assisted the patient while doing prone position and used multiple pillows for making pasien more comfortable and avoid pain with duration two hours per session with a target of 8 hours a day. ${ }^{19}$ Most of these studies stopped the prone positioning if the patient was intolerant, had worsening hypoxia, or observed increased work of breathing.

\section{Measured outcome}

There are several outcomes evaluated in studies in this systematic review. Burton-Papp et al. examine the changes in oxygenation by measuring the ratio of $\mathrm{PaO} 2$ and $\mathrm{FiO} 2 . \mathrm{PaO} 2$ is the oxygen partial pressure in the artery, while $\mathrm{FiO} 2$ is the fraction of inspired oxygen. ${ }^{5}$ The other study that also measured the $\mathrm{PaO} 2 / \mathrm{FiO} 2$ ratio was studied by Coppo et al., which measured the change of $\mathrm{PaO} 2 / \mathrm{FiO} 2$ ratio between prone positioning and one hour after resupine as an index of pulmonary recruitment. $^{7}$ Study by Fazzini also measured the $\mathrm{PaO} 2 / \mathrm{FiO} 2$ ratio and also the $S / F$ ratio that defined as the ratio of the peripheral capillary oxygen saturation to a fraction of inspired oxygen. ${ }^{9}$ They also measured the change of respiratory rate and ICU admission after prone positioning.

Four studies are comparing the change of oxygenation between the prone and non-prone group; they are studied by Jagan et al., Jouffroy et al., Kharat et al., and Syrma et al. ${ }^{7,11,18,19}$ Study by Jagan et al., also used S/F ratio as the outcome for their study concomitant with intubation and mortality rate between the prone and non-prone patient. ${ }^{10}$ While the study by Jouffroy et al. measured the $\mathrm{PaO} 2 /$ $\mathrm{FiO} 2$ and $\mathrm{PaCO} 2 .{ }^{17}$ Study by Kharat et al. measured the needs of oxygen and S/F ratio between two groups. ${ }^{18}$ Study by Sryma et al. measured the rate of intubation and mortality and ROX index. ROX index is used as a predictor of whether the HFNC therapy is successful or not. ROX index is calculated from $\mathrm{SpO} 2 / \mathrm{FiO} 2$ (\%) divided by respiratory rate (breaths/minute). The ROX index reflects the objective measure of work of breathing. ${ }^{19}$

A study by Caputo et al. measured the $\mathrm{SpO} 2$ in the patient five minutes after prone positioning and measured the intubation rate after 24 hours presentation to the emergency department. The other study that also measured the SpO2 was a study by Damarla et al., which also measured the change in the respiratory rate before proning and one hour after initial proning. ${ }^{6}$ They also measured the 
intubation rate after two weeks of the first prone positioning trial as the second parameter. A study by Winearls et al. also used the ROX index as an outcome parameter, adding the change of $\mathrm{SpO} 2$ and $\mathrm{PaO}_{2} / \mathrm{FiO}_{2}$ between baseline and after prone positioning. ${ }^{20}$ The last is a retrospective study by Wormser et al. measure $\mathrm{S} / \mathrm{F}$ ratio before, during, and after prone position, presentation of failure and adverse events such as desaturation, change in blood pressure or heart rate, vomiting during prone position, and intolerance while doing prone positioning due to subjective reasons such as worsening of dyspnea, discomfort, anxiety or pain..$^{21}$

\section{DISCUSSION}

\section{Physiological mechanism technique of prone positioning}

and

The prone position technique was firstly discovered by Piehl and Brown in 1976 when they observed better oxygenation in respiratory insufficiency patients placed in the prone position. This observation was concurred by Douglas et al. in 1977 that reported improved oxygenation in a patient with acute lung insufficiency when the patients changed from supine to prone position. ${ }^{11,13}$ At first, prone positioning was suggested in 1974 as a protective lung strategy method for patients with ARDS. ${ }^{4}$ There are several underlying physiological mechanisms of prone positioning in improving oxygenation, which is multifactorial. The main mechanisms are reducing lung compression and improving lung perfusion. The first is gravitation; alveolar distention varies regionally because of the anatomic relationship with the chest wall and heart. A relatively decreased lung volume collapsed in the prone position compared with the supine position that is eventually reduced the lung compression., ${ }^{4,11}$ The second is, vascular conductance was higher in the dorsal part of the lungs than in the ventral region. The prone position makes the pulmonary ventilation-perfusion matching improved. The third is that prone positioning minimizes the difference of transpulmonary pressure between the dorsal and ventral part of the lung, causing dispersion of tidal volume more homogenous, thus minimizing alveolar stretch and strain. It leads to a decrease in ventral alveolar over-inflation and alveolar collapse in the dorsal part of the lung. The reduced alveolar distension will allow the opening of alveoli that collapsed during supine position. All of that mechanism resulted in improvements in oxygenation that may reduce the mortality rate due to hypoxia. ${ }^{13-15}$

The indication of prone positioning is for the acute hypoxemic respiratory patient marked by oxygen saturation only for alert and conscious patients. While the contraindications are signed respiratory distress such as increased work of breathing, urgent need for intubation, unstable hemodynamic or arrhythmia, $\mathrm{PaO} 2 / \mathrm{FiO} 2$ less than 100 in NIV or HFNC, agitation or altered mental status or seizure, unstable spine or thoracic injury, pregnancy particularly second and third trimester, recent abdominal surgery, obesity, and massive hemoptysis. Prone positioning can be assisted by the physical therapy team or other health care team members and can do with or without supplemental oxygenation. Prone positioning is suggested to do in a reverse Trendelenburg position. Prone positioning also may need pillows to support the chest, as we can see in Figure 2. There is not yet a specific time to do prone positioning based on the guideline. While the patient is prone positioning, it is important to monitor the oxygen saturation and respiratory rate. After 15 minutes of prone positioning, we need to evaluate whether there is desaturation or patient intolerance. The prone positioning should stop if there is a sign of respiratory distress, the ROX index below $92 \%$. Especially for awake-proning,

$\leq 2.85$ at 2 hours and $\leq 3.47$ at 6 hours that suggest poor response and should prompt advanced treatment such as ICU admission or the need for mechanical intubation or improvement in oxygen saturation to more than $93 \%$ room air after 2 hours stopping prone positioning can be maintained. ${ }^{12,13,16}$

\section{Effect of prone positioning in improving oxygenation}

Based on our qualitative analysis, all eleven studies proved that prone positioning helps to improve oxygenation in COVID-19 patients. A study by BurtonPapp et al. found that prone positioning in conscious COVID-19 patients combined with non-invasive ventilation can improve oxygenation, thus decreasing the requirement for invasive ventilation and potentially giving better overall outcomes. They found that after the patient did five cycles and a duration of 3 hours for each cycle, there was an increment in $\mathrm{PaO} 2 /$ FiO2 (P/F) approximately $28.7 \mathrm{mmHg}$, but no significant change in heart rate or respiratory rate. They suggested that prone positioning in an awake patient with noninvasive ventilation may be considered as an initial therapeutic intervention to overcome moderate acute hypoxic respiratory failure in COVID-19 patients. ${ }^{5}$

The relationship between prone positioning with improved oxygenation in COVID-19 can be explained through the pathophysiology of the disease. In the COVID-19 infection, lungs were inhomogeneous, and CT-scan results depict a ground-glass opacity which later turned into a linear consolidation. In the

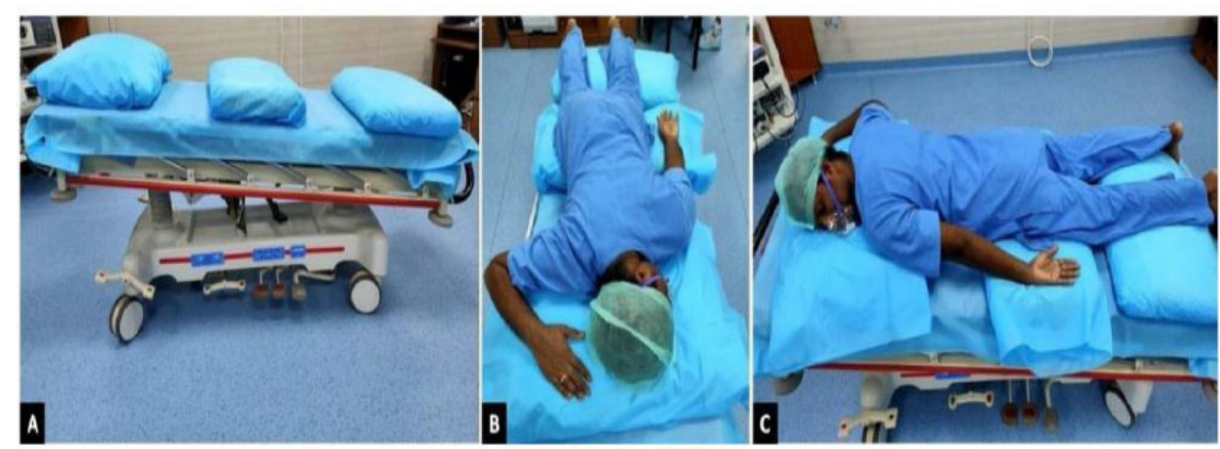

Figure 2. (A) The suggested bed position in prone positioning is reverse Trendelenburg (minimal $\left.30^{\circ}\right)$. (B) the prone positioning as viewed from the cranial end. (C) The position of the patient while doing prone positioning; pillows can be used to support the head, pelvis and legs..$^{12,13}$ 
COVID-19 patient's lungs also found exudation, macrophage infiltration, fibrosis and mucous blockage. Prone positioning will help the drain secretions from lug peripheries, thus improving lung ventilation and perfusion. ${ }^{5,10}$ Study by Caputo et al. also stated that prone positioning would help to decrease respiratory effort in moderate to severe COVID-19 patients, which proved from their study result that median oxygen saturation in COVID-19 patients increased to $94 \%$ after 5 minutes did prone positioning. ${ }^{6}$ In line with those studies, a study by Damarla et al. also found a decreased respiratory rate from $31 \mathrm{x} /$ minute into $21 \mathrm{x} /$ minute after prone positioning. They also found that after 1 hour did prone position, median oxygen saturation in COVID-19 patients increased significantly from $94 \%$ to $98 \%{ }^{8}$ Study by Coppo et al. supports the feasibility of prone positioning in spontaneously breathing COVID-19 patients. This finding is in line with other studies, such as a study by Jouffroy et al. They found that spontaneously breathing prone positioning (SBPP) was well tolerated hemodynamically and significantly increased $\mathrm{PaO} 2 / \mathrm{FiO} 2$ ratio in COVID-19 patients who did SBPP compared to nonSBPP patients.?

A study by Fazzini found that prone positioning resulted in significant oxygen improvement from the P/F ratio, lower respiratory rate, lower work of breathing and lower shortness of breath after 1-hour prone-positioning. ${ }^{9}$ A cluster randomized controlled trial by Kharat found that patients who did self-prone positioning needed a lower oxygen therapy compared with the control group. The self-prone positioning group also had an improved SpO2/FiO2 ratio. $^{18}$ Study by Winearls et al. found that group of patients who did prone positioning had greater ROX index, indicating that further disease progression could be avoided by doing prone positioning through decreasing breathing effort and less risk for intubation. ${ }^{20}$ Studies by Sryma et al. also found a similar result; they found a higher ROX index in COVID patients with prone positioning than in the non-prone patient. The transpulmonary pressure, defined by the difference between airway opening and pleural pressure, is decreased by prone positioning, thus improving gas exchange. The intrathoracic and abdominal viscera weight is unloaded from the lungs and relieved by restricted diaphragm by prone positioning. ${ }^{19}$ Additionally, prone positioning increases the aeration of poorly ventilated alveoli. Concisely, prone positioning improved oxygenation in the lungs by distributing aeration homogenously, ventilation and perfusion improvement, increased mucous clearance and giving lung protection. ${ }^{11,12,19}$

\section{Effect of prone positioning in reducing intubation and mortality rate}

Fazzini et al. found that patients who did prone positioning more than one hour a day had lower ICU admissions and tracheal intubation than patients who did prone positioning for less than one hour a day. But no difference in the hospital length of stay and the 90-day mortality rate was found. ' Study by Jagan et al. also found that awake patients who did self-prone positioning have decreased intubation risk by $69 \%$. But their study also found that older and more severe patients were less likely to do self-proning successfully. ${ }^{10}$ Study by Sryma et al. also found that the control group's intubation and the mortality rate were higher. Prone positioning is low-cost, applicable, and easy to implement, especially in low-and middle-income countries experiencing oxygen and mechanical ventilation shortages during the high peak of the COVID-19 pandemic. Prone positioning in awake and spontaneously breathing patients helps decide in ventilator triage for patients with severe or critical COVID-19 infection and non-COVID patients requiring mechanical ventilation. ${ }^{19}$

\section{Adverse event}

We found most of the studies stated no adverse event with the prone positioning method from the analysis. A study by Fazzini et al. stated that self-prone positioning in awake and non-intubated COVID-19 patients was not associated with any adverse effects or treatmentrelated complications. ${ }^{9}$ There is only one study by Wormser et al. reported the adverse event of prone positioning, but not serious. They found a 5\% failure rate of prone position due to anxiety, desaturation, pain, and discomfort. ${ }^{21}$ Five patients died during the follow-up in the study by Coppo et al., but it was stated due to underlying disease and unrelated to study procedure. ${ }^{7}$

\section{CONCLUSION}

Based on our analysis results, all studies stated the beneficial effect of prone positioning in improving oxygenation in COVID-19 patients. Improving oxygenation is marked by increased oxygen saturation, the $\mathrm{PaO} 2 / \mathrm{FiO} 2$ ratio, the $\mathrm{SaO} 2 / \mathrm{FiO} 2$ ratio, the $\mathrm{ROX}$ index, and decrease of respiratory rate, work of breathing, shortness of breath, intubation and mortality rate. The adverse event of this method is minimal, and no death related to prone positioning was observed. This is a feasible method that can be applied to overcome oxygen and mechanical ventilation shortage in a condition where the COVID-19 case is rapidly rising. More multicentered randomized controlled should be done to provide a more reliable and evident result with a minimum bias regarding the role of prone positioning in COVID-19 patients.

\section{CONFLICT OF INTEREST}

There is no competing interest regarding the manuscript.

\section{FUNDING}

None.

\section{AUTHOR CONTRIBUTION}

I Made Yoga Prabawa, Dedi Silakarma, and Sisca Susantio are responsible for the study from the conceptual framework.

\section{REFERENCES}

1. World Health Organization. Coronavirus disease (COVID-19): 2021

2. Kemenkes RI. Situasi Terkini Perkembangan Novel Coronavirus (Covid-19). 2021 Retrieved October 28, 2021, Available in: https://covid19. kemkes.go.id/situasi-infeksi-emerging/infocoronavirus/situasi-terkiniperkembangancoronavirusdisease-covid-19-28 september2021/\#.X0y2bNwzZxQ

3. World Health Organization. Coronavirus Disease 2019 (COVID-19) Situation Report65. Retrieved October 20, 2021. Available in: https://cdn.who.int/media/docs/defaultsource/searo/indonesia/covid19/external- 
situation-report-65_28-july-2021-final. pdf?sfvrsn=a7697f51_5

4. Petrone P, Brathwaite CE, Joseph DAK. Prone ventilation as treatment of acute respiratory distress syndrome related to COVID-19. European Journal of Trauma and Emergency Surgery. 2021; 47(4):1017-1022. https://doi.org/10.1007/s00068-020-01542-7

5. Burton-Papp HC, Jackson AI, Beecham R, Ferrari M, Nasim-Mohi M, Grocott MP. Conscious prone positioning during noninvasive ventilation in COVID-19 patients: experience from a single centre. F1000Research. 2020.9 9. https://doi.org/10.12688/ f1000research.25384.1

6. Caputo ND, Strayer RJ, Levitan R. Early selfproning in awake, non-intubated patients in the emergency department: a single ED's experience during the COVID-19 pandemic. Academic Emergency Medicine. 2020; 27(5): 375-378. doi: 10.1111/acem.13994

7. Coppo A, Bellani G, Winterton D, Di Pierro M, Soria A, Favero P, Foti G. Feasibility and physiological effects of prone positioning in non-intubated patients with acute respiratory failure due to COVID-19 (PRON-COVID): a prospective cohort study. The Lancet Respiratory Medicine. 2020; 8(8): 765-774. https://doi.org/10.1016/S2213-2600(20)30269$\underline{1}$

8. Damarla M, Zaeh S, Niedermeyer S, Merck S, Niranjan-Azadi A, Broderick B, Punjabi N. Prone positioning of non-intubated patients with COVID-19. American journal of respiratory and critical care medicine. 2020; 202(4): 604-606. https://doi.org/10.1164/ rccm.202004-1331LE

9. Fazzini B, Fowler AJ, Zolfaghari P. Effectiveness of prone position in spontaneously breathing patients with COVID-19: A prospective cohort study. Journal of the Intensive Care Society. 2021. 1751143721996542. DOI: $10.1177 / 1751143721996542$

10. Jagan N, Morrow LE, Walters RW, Klein LP, Wallen TJ, Chung J, Plambeck RW. The
POSITIONED study: prone positioning in nonventilated coronavirus disease 2019 patients-a retrospective analysis. Critical care explorations. 2020; 2(10). DOI: 10.1097/ CCE.0000000000000229

11. Lindahl SG. Using the prone position could help to combat the development of fast hypoxia in some patients with COVID-19. Acta Paediatrica. 2020; 109(8): 1539-1544. DOI: 10.1111/apa.15382

12. Stilma W, Åkerman E, Artigas A, Bentley A, Bos LD, Bosman TJ, Van Der Woude MC. Awake proning as an adjunctive therapy for refractory hypoxemia in non-intubated patients with COVID-19 acute respiratory failure: guidance from an international group of healthcare workers. The American Journal of Tropical Medicine and Hygiene. 2021; 104(5): 1676. doi:10.4269/ajtmh.20-1445

13. Bentley SK, Iavicoli L, Cherkas D, Lane R, Wang E, Atienza M, Kessler S. Guidance and Patient Instructions for Pruning and Repositioning of Awake, Non-Intubated COVID-19 Patients. Academic Emergency Medicine. 2020. doi: $10.1111 /$ acem.14067

14. Sud S, Friedrich JO, Adhikari NK, Taccone P, Mancebo J, Polli F, Guérin C. Effect of prone positioning during mechanical ventilation on mortality among patients with acute respiratory distress syndrome: a systematic review and meta-analysis. Cmaj. 2014;186(10): E381-E390. DOI:10.1503/cmaj.140081

15. Slessarev M, Cheng J, Ondrejicka $M$, Arntfield R. Patient self-proning with highflow nasal cannula improves oxygenation in COVID-19 pneumonia. Canadian Journal of Anesthesia/Journal Canadien d'anesthésie. 2021;67(9):1288-1290. https://doi.org/10.1007/ s12630-020-01661-0

16. Raoof S, Nava S, Carpati C. High flow, noninvasive ventilation and awake (non-intubation) proning in patients with COVID-19 with respiratory failure. Chest. 2020. DOI: https:// doi.org/10.1016/j.chest.2020.07.013
17. Jouffroy R, Darmon M, Isnard F, Geri G, Burton A, Fartoukh M, Vieillard-Baron A. Impact of prone position in non-intubated spontaneously breathing patients admitted to the ICU for severe acute respiratory failure due to COVID-19. Journal of critical care. 2021; 64: 199-204. https://doi.org/10.1016/i. jerc.2021.04.014

18. Kharat A, Dupuis-Lozeron E, Cantero C, Marti C, Grosgurin O, Lolachi S, Adler D. Self-proning in COVID-19 patients on lowflow oxygen therapy: a cluster randomised controlled trial. ERJ Open Research. 2021; 7(1). https://doi.org/10.1183/23120541.00692-2020]

19. Syma PB, Mittal S, Mohan A, Madan K, Tiwari P, Bhatnagar S, Baldwa B. Effect of proning in patients with COVID-19 acute hypoxemic respiratory failure receiving non-invasive oxygen therapy. Lung India: Official Organ of Indian Chest Society. 2021; 38(Suppl 1): S6. DOI: 10.4103/lungindia.lungindia_794_20

20. Winearls S, Swingwood EL, Hardaker CL, Smith AM, Easton FM, Millington KJ, Curtis KJ. Early conscious prone positioning in patients with COVID-19 receiving continuous positive airway pressure: a retrospective analysis. BMJ Open Respiratory Research. 2020; 7(1): e000711. doi:10.1136/bmjresp-2020-000711

21. Wormser J, Romanet C, Philippart F. Prone position inwards for spontaneous breathing Covid-19 patients: a retrospective study. Irish Journal of Medical Science. 2021;1971:: 1-4. https://doi.org/10.1007/s11845-020-02479-x

22. The Joanna Briggs Institute. Reviewer's Manual. Australia: The Joanna Briggs Institute; 2014.

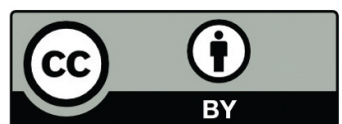

This work is licensed under a Creative Commons Attribution 